\title{
Discussion on Core Risk Control Index and Dynamic Monitoring System of Securities Companies
}

\author{
Chenyin Sun
}

School of Economics Shanghai University, Jingan, Shanghai, China

\author{
24924580@qq.com \\ ${ }^{*}$ Chenyin Sun
}

\begin{abstract}
Keywords: Securities companies, Core risk control index, Dynamic monitoring
\end{abstract}
\begin{abstract}
Securities companies have entered the era of comprehensive risk management. The core risk control index system of securities companies is the core element of risk control and management of China's securities companies. Establishing and constantly improving the risk control index system of China's securities companies is of great significance to promote the normative development of China's securities companies and enhance the risk management ability of domestic securities companies. In order to build the system well, it must be realized by means of the core risk control index dynamic monitoring system. Taking core risk control index and dynamic monitoring system as the starting point, the utility can be maximized by strengthening the business risk management and effective asset allocation of securities companies. This paper discusses the core risk control indicators and dynamic monitoring system of securities companies and the direction of improvement.
\end{abstract}

\section{证券公司核心风控指标与动态监控体系探讨}

\author{
孙晨音 \\ 上海大学经济学院, 静安, 上海, 中国 \\ 24924580@qq.com \\ “孙晨音
}

关键词：证券公司；核心风控指标；动态监控

中文摘要.证券公司进入全面风险管理时代, 证券公司核心风控指标体系是我国证券公司风险 控制管理的核心要素。建立并不断完善我国证券公司风险控制指标体系对促进我国证券公司 的规范性发展、提升国内证券公司风险管理能力具有重要意义。而为了做好该体系建设, 必 须借助核心风控指标动态监控系统来实现。以核心风控指标与动态监控体系为出发点, 加强 证券公司业务风险管理、资产的有效配置, 才能实现效用最大化。本文旨在讨论研究证券公 司核心风控指标及动态监控体系运行情况及改进的方向。

\section{1. 证券公司核心风控指标体系}

目前国内证券公司设定的核心风控指标体系主要遵照中国证监会《证券公司风险控制指 标管理办法》及配套规则确定，即以净资本和流动性为核心的风险控制指标体系。国内所有 券商均已建立起以核心风控指标监控与管理为基本的风险管理体系。通过动态监控系统实现 
对证券公司的核心风控指标的实时监控和动态补足, 时刻保持证券公司各业务规模与其资本 水平、流动性状况、风险特性相匹配, 实现资源使用效率最大化。

\section{1 我国证券公司风险控制指标体系的发展历程}

我国证券公司风险控制指标体系从2006年推出后，经历了多次修订完善。

2006年, 证券法确立了净资本等风险控制指标的法律地位; 同年7月, 证监会正式实施《证 券公司风险控制指标管理办法》。

2007年，证监会因新会计准则变化影响发布证券公司净资本计算标准调整通知。

2008年，证监会发布《证券公司风险控制指标管理办法》及其配套文件，要求证券公司 建立以净资本为核心的证券公司风险控制指标体系，推动了证券公司风险的透明化，在管理 证券公司各项业务风险，夯实证券公司财务基础，保持证券公司业务规模与资本实力相匹配 等方面发挥了重要作用。

2010年至2015年，证监会根据证券公司创新业务发展情况，陆续下发7项指引文件，规范 证券公司融资融券业务、自营业务等业务风险控制指标监管报表的填报口径，加强证券公司 核心业务的监管工作。

现行风险控制指标体系是中国证监会于2016年发布的修订后的《证券公司风险控制指标 管理办法》及配套规则。新版体系主要改进的内容有：一是改进净资本、风险资本准备等关 键指标计算公式, 提升资本质量和风险计量的针对性; 二是完善杜杆率指标, 提高风险覆盖 的完备性; 三是优化流动性监控指标，强化资产负债的期限匹配；四是完善单一业务风控指 标, 提升指标的针对性; 五是明确逆周期调节机制, 提升风险控制的有效性; 六是强化全面 风险管理要求，提升风险管理水平。

随后证监会仍然不断修订和探索证券公司核心风控指标监管规定，于2018年针对资产管 理业务中的股票质押业务提出增加特定风险准备计提的要求。于2019年结合市场情况和证券 公司发展需要，对《证券公司风险控制指标计算标准》新修订稿向社会公开征求意见。

\section{2 核心风控指标的研究情况}

国内各界对于证券公司风险控制指标体系已有诸多研究材料，但对2016年后新版规定的 讨论相对较少。其中较为适用的研究论点有吕祥友、孙永文、胡开南(2015)通过对证券公司 风险控制指标的计算和动态监控模式的研究, 提出风险控制指标动态监控适用综合计算模式 数据较为准确, 但实现方式复杂。焦娜 (2019) 对证券公司风险控制指标体系完善研究, 提 出加强风险管理理念和管理机制建设、拓宽融资渠道，降低流动性风险、利用压力测试技术 和方法制定针对性风险解决方案以提高核心风险控制指标体系的进一步完善。从各期刊文献 材料来看, 现行指标在管理监控中仍然存在改进提升空间, 随着证券行业的持续发展, 市场 环境、业态环境的不断变化，对证券公司核心风险控制指标的管理和监测应与时俱进，不断 提高。

\section{2. 核心风控指标管理对证券公司风险管理的重要性}

\section{1 帮助证券公司建立健全量化风险控制指标体系}

为保障证券公司核心风险控制体系的有效管理，2016年证券业协会修订了《证券公司全 面风险管理办法》、《证券公司风险控制指标动态监控系统指引》等配套规则, 推出实施三 年来，帮助证券公司进一步完善了全面风险管理机制，建立符合证券公司特点的组织架构、 制度体系、人才队伍、量化风险控制指标体系、风险控制信息系统、风险应对措施等关键重 点。在量化风险控制指标体系中, 核心风险控制指标作为基础出发点确立了不可突破的监管 底线限额, 确保证券公司的风险管理既能够满足监管要求, 又保障公司在风险可控的前提下 开展业务, 优化资源配置, 实现效益最大化。 
表1＼cjkstart证券公司核心风控指标及阀值列表

\begin{tabular}{|c|c|c|c|}
\hline \multirow{2}{*}{ 券商核心风 } & \multicolumn{3}{|c|}{ 重要风控指标限额阀值 } \\
\cline { 2 - 4 } & 风控指标名称 & 指标预警限额 & 指标禁止限额 \\
\hline 1 & 风险覆盖率 & $>=120.00 \%$ & $>=100.00 \%$ \\
\hline 2 & 资本杜杆率 & $>=9.60 \%$ & $>=8.00 \%$ \\
\hline 3 & 流动性覆盖率 & $>=120.00 \%$ & $>=100.00 \%$ \\
\hline 5 & 净稳定资金率 & $>=120.00 \%$ & $>=100.00 \%$ \\
\hline 6 & $\begin{array}{c}\text { 自营权益类证券及其 } \\
\text { 衍生品/净资本 }\end{array}$ & $<=80.00 \%$ & $<=100.00 \%$ \\
\hline & $\begin{array}{c}\text { 自营非权益类证券及 } \\
\text { 其衍生品/净资本 }\end{array}$ & $<=400.00 \%$ & $<=400.00 \%$ \\
\hline
\end{tabular}

\section{2 帮助证券公司进行科学有效的资源配置}

证券公司在进行各项资产配置、开展新业务时都要考虑新业务变动对公司风险承受能力 的影响程度。国内证券公司主要借助核心风险控制指标压力测试等风险管理工具评估风险承 受能力, 为经营决策提供数据支持。有效利用压力测试技术, 可以评估出公司核心风控指标 在压力情景下的敏感性水平，使得证券公司在事前权衡好业务发展与风险承受之间的量化关 系，帮助证券公司稳健有效的进行资产配置。

\section{3 帮助证券公司实时监测流动性风险水平，及时进行资本补足}

通过核心风险控制指标中流动性覆盖率、净稳定资金率的测算，能够刻画出证券公司短 期和中长期流动性风险管理情况。为避免因市场原因、公司经营问题带来资金断裂的流动性 风险，核心风控指标的管理可以指导证券公司对做好资产负债到期匹配管理、强化日间流动 性管理、加强优质资产流动性储备等措施，以有效防范突发性流动性风险。同时通过指标监 测能够及时观察到公司流动性风险状况，在事前、事中提醒证券公司及时采取通过长、短期 融资手段化解公司流动性不足、资本不足的风险。

下表2显示, 研究抽选出的上市证券公司均严格控制流动性风险控制指标远离监管限额标 准。而各项风险控制指标的水平也将影响到证券公司分类评级，根据《证券公司分类监管规 定》, 证券风控指标连续达标的在年度分类评级中将得到加分, 分类评级的高低也将影响到 证券公司业务资格的申请、融资利率、投保基金提交比例等要素，这都证明了核心风控指标 对证券公司的重要性。

表2 上市券商流动性风险指标情况

\begin{tabular}{|c|c|c|c|c|c|c|}
\hline \multirow{2}{*}{ 风控指标名称 } & \multicolumn{5}{|c|}{ 上市证券公司2018年年报中流动性风控指标情况 } \\
\cline { 2 - 7 } & 海通证券 & 华泰证券 & 广发证券 & 第一创业 & 天风证券 & 浙商证券 \\
\hline 流动性覆盖率 & $477.91 \%$ & $648.34 \%$ & $404.53 \%$ & $161.51 \%$ & $862.28 \%$ & $283.30 \%$ \\
\hline 净稳定资金率 & $137.11 \%$ & $140.95 \%$ & $139.77 \%$ & $159.52 \%$ & $156.04 \%$ & $133.21 \%$ \\
\hline 证券公司评级 & $\mathrm{AA}$ & $\mathrm{AA}$ & $\mathrm{AA}$ & $\mathrm{BBB}$ & $\mathrm{A}$ & $\mathrm{A}$ \\
\hline
\end{tabular}

\section{4 帮助证券公司建立动态监控工作体系与动态监控系统}

证券公司核心风险控制指标动态监控是指以集中的信息系统为技术支撑的、对公司各类 业务信息进行收集清洗，按规则每日计算生成风险控制指标并实行风险监控的管理模式。

风险控制指标动态监控系统的建立和完善为公司实施全面风险管理奠定信息技术基础。 风险控制指标动态监控系统通过搭建数据仓库, 实现数据的集中采集、集中存储、集中管理。 采集的数据包括交易数据、财务数据、清算数据、自营数据、资产管理数据、柜台业务数据、 
场外业务数据以及资讯数据等, 另外各证券公司可根据业务发展和管理需要, 拓展采集数据 的范围与深度。

\section{3. 现行核心风控指标与动态监控体系存在的问题}

\section{1 核心风控指标体系存在的问题}

在市场持续低迷的情况下，监管对指标应实施逆周期调节，引导行业优化资本配置。针 对证券公司的不同业务、产品的风险特征, 实施宽严相济的指标调整, 发挥风控指标计算标 准的导向作用, 提升资本市场流动性, 支持行业健康有序发展。

三年来，证券行业创新业务持续涌现，应明确新业务计算标准，提升风控指标完备性。 根据市场发展情况和行业实践中的新业务、新情况，及时明确相关指标计算标准，确保风控 指标对公司各类业务的全覆盖。

应结合证券公司分类评价结果强化差异化监管，提升合规风控有效、业务拓展能力较强 的证券公司的资本运作空间。

\section{2 核心风控指标动态监控体系存在的问题}

核心风控指标的有效动态监控不仅要求证券要具有一定风险管理水平，安排具有专业知 识的风控人员每日对公司风险情况进行监控，同时更要注重数据质量的管理工作。核心风控 指标动态监控系统涉及证券公司几乎所有条线数据, 所需对接的系统繁多, 且各系统还要必 须及时、真实、完整提供数据。因此, 无论任何环节出现问题, 均会影响指标生成的准确性, 这就需要证券公司提高内部数据质量管理, 将核心风控指标动态监控系统取数从一对多的状 态改为一对一的状态, 加强公司统一数据中心建设, 不断完善数据接口更新及数据准确性校 验机制, 确保核心风控指标动态监控系统及时采取到准确的数据信息，逐步完善风险控制指 标动态监控模型，从而更加真实地反映公司的风险状况。

\section{4. 现阶段证券公司核心风控指标与动态监控体系改进建议}

\section{1 核心风控指标体系改进的建议}

监管部门应考虑对于国内证券公司业务特性调节核心风控指标计算标准。例如：对投资 对冲风险策略，证券公司通过买入与现货方向相反的空头期货对冲市场风险，在对冲标准没 有达到监管规定的情形下仍按照绝对值计算风险准备将高估证券公司的实际风险敞口，可考 虑适当降低方向相反有对冲目的市场风险准备计提标准; 可引导证券公司进行价值投资, 鼓 励证券公司深度参与市场交易，将投资成分股、权益类指数基金产品的市场风险准备计算标 准下调; 对于证券公司通过债券借贷、买断式回购借入的债券卖空的，应考虑其需要到期购 回的特点，额外计算市场风险准备等。

监管部门应考虑不断结合证券新业务、新风险, 明确风险计算标准。近年来国内证券市 场创新业务飞速发展, 在衍生品业务中, 国内开展试水信用衍生品业务, 应在风险可控的前 提下明确证券公司开展信用业务的风险指标计算标准; 科创板是2019年国家为建立多层次的 资本市场结构又一重要政策，针对科创板高风险、高波动特性应设计异于指数成分股、一般 上市股票的市场风险计算比例；对于债券质押式融资回购经纪业务交易结算模式下，证券公 司作为结算参与人可能承担潜在结算风险，应考虑计算经济业务待回购交易金额的信用风险 准备。

为支持证券公司提升全面风险管理水平，在风控有效的前提下进一步发展，可在现行风 险资本准备调整系数的基础上，可考虑增加连续多年风险评级为A类AA级别的证券公适当降 低其风险准备计提标准。在对证券公司进行风险评级时, 将证券公司全面风险管理能力、核 心风控指标管理力纳入考核范围, 对于不同规模的证券公司制定区别的评判标准, 以鼓励各 层级证券公司打造有特点的品牌。 


\section{2 核心风控指标动态监控体系改进的建议}

虽然监管部门不断修订推出证券公司风险控制指标管理办法及配套措施, 但由于各证券 公司风险管理水平和管理体系不同，其核心风控指标的测算方法大不相同，尤其是在月中核 心风控指标的测算, 存在较大的差异性和波动性, 不利于数据统计和证券公司风险管理使用。 因此, 建议监管部门建立更加完善、明细的核心风险控制指标计算方法, 严格督促证券公司 落实执行, 确保以核心风控指标的动态监控有效发挥作用。例如在计算客户融资类业务规模 占净资本比例时, 由于会计准则的变动, 客户负债中应加上应付利息金额，但由于应付利息 核算每月开展一次，因此无法准确于月中获取客户融资类业务负债金额。可考虑将客户融资 利率按日计算应付利息, 由监控系统自动统计客户利息并计算指标结果, 以提升月中核心风 控指标计算准确性。

\section{References}

[1] Na Jiao, Perfect research on risk control index system of securities companies, Contemporary accounting, vol.05, pp. 107-108, 2019.

[2] Xiangyou Lv,Yongwen Sun, and Nankai Hu,Study on dynamic monitoring and improvement of risk control index system of securities companies, Shangdong Social Sciences, vol.3, pp. 127-131, 2015.

[3] $\mathrm{Yu} \mathrm{Gu}$, Research on improvement of risk control index of current securities companies, Search, vol. 10, pp. 100-104, 2015.

[4] Qingsu Qing, On the risk control of securities companies with net capital as the core, Times Finance, vol.6, pp. 164-172, 2014. 